\title{
Determinants of the Policy Impact of Analytical Communities in Russian Regions: Cases of Karelia, Tatarstan and Saratov
}

\begin{abstract}
This paper evaluates the policy impact of analytical communities in three Russian regions (Karelia, Tatarstan and Saratov). Based on the existing methods to assess the political power of think tanks, the authors develop a method to evaluate this impact. The authors test this method using the empirical data and findings from interviews, workshops with representatives of analytical communities of the three regions, and from observations and assessments of experts in regional politics. In conclusion, the authors argue that the capacity of analytical communities to impact policy change in a region depends on the level of political competition and pluralism and democratic institutions in the region; the level of consolidation of the analytical community, its autonomous political status and authority.
\end{abstract}

KEYWORDS: Think tanks, analytical communities, political power, influence, policy impact

RECEIVED 17 October 2016; ACCEPTED 1 August 2017.

\section{INTRODUCTION}

The consideration of policy making as a top-down process, as an activity exclusively or primarily of state and municipal authorities, overlooks the effect of non-state actors on the policy making process such as NGO's, associations of business, and think tanks. The complication of political processes in modern societies led to the rise of importance of policy specialists - intellectuals, who have special knowledge in public policy and specific expertise in diverse policy fields. Efficient policy-making without those actors and their knowledge become impossible (Dahl, 1989). To increase the quality of governance, the demand for independent policy advice has increased. That is why, it is important to understand the power, influence and policy impact of such independent policy specialists. In the literature, such actors are described in different ways: think tanks (Zaytsev, 2010), 'boundary workers' (Hoppe, 2009), 'policy advisers', 'knowledge producers', 'knowledge brokers' (Howlett \& Craft, 2013), 'epistemic communities' (Haas, 1992), and so on. These notions highlight different aspects of one phenomenon - intellectuals, who provide professional applied policy analysis for policy-makers. If such intellectuals are structured in an organization, which enjoys autonomy from the government, it is a think tank. Boundary work theory pays attention to such aspects of policy specialists' activity as being between science, on the one hand, and politics and policy-making, on the other, translating relevant scientific knowledge for decision-makers to increase the efficiency of their decisions. The policy specialists' function of brokerage is emphasized when they are labelled as the 'knowledge brokers'. The function of the generation of policy relevant information is carried out by 'knowledge producers'. The 'epistemic community' concept helps to define the community of policy specialists in each policy field (such as professionals in health policy, foreign policy, or education policy). Those who use the notion of 'policy advisers' try to describe the system of policy advice in a particular country or policy field, with diverse types of policy-makers interacting with different kinds of policy advisers. This paper uses the broader term, 'analytical communities', to define policy specialists or intellectuals who are active in public policy and provide policy-relevant advice for decision-makers. When we change the focus of our analysis from global or national levels with high levels of differentiation of social and political functions and roles, to the local level, where you can find less diversity, we can see that all the above-mentioned functions and roles of policy specialists exist; but usually they are neither institutionalized in organizations, such as think tanks, nor consolidated in different communities by common shared roles, functions, and discourses.

\footnotetext{
* Dmitry Zaytsev: International Laboratory for Applied Network Research, Public Policy Department, National Research University Higher School of Economics.
}

Nina Belyaeva: Public Policy Department, National Research University Higher School of Economics. Emails: dzaytsev@hse.ru, nbelyaeva@hse.ru. 
The next problem is that all these types of policy specialists were defined for liberal democracies, in case studies of public policy mostly in North America and Western Europe. Policy specialists exist in other types of political regime but not necessarily represented by such kinds of organizations as think tanks and communities as 'boundary workers' or 'knowledge brokers'. Because of these, both in regions and municipalities, and in non-western societies, the same person or community, depending on the situation, can fulfil different roles (produce knowledge, brokerage, boundary work, expertise in particular policy domain or of special policy issue, etc.). But what is common is their function to provide policy-relevant analysis for decision-makers to improve public policy in the municipality, region, or country. That is why, instead of narrower definitions, such as 'boundary workers', 'knowledge producers', 'knowledge brokers', 'epistemic communities', we propose to use a broader concept - 'analytical communities'.

Sometimes in the literature, the term think tank has a broader meaning; the authors are trying to stretch this concept to catch all possible communities, who are active in global and national public policy (McGann \& Johnson, 2006; McGann \& Sabatini, 2010, McGann, 2015). It is well-known that think tanks are an American phenomenon, and first appeared in the USA; then this phenomenon spread all over the world (McGann \& Sabatini, 2010). If we try to find think tanks that meet all the characteristics of exemplary American Think Tanks, in other countries, we will hardly find them outside the USA. The notion of think tanks was stretched to explain similar phenomena. That is why in literature, different traditions of think tanks are used: Anglo-American, European, and Asian (Stone \& Denham, 2004). 'The notion that a think tank requires independence or autonomy from the state in order to be "free-thinking" is a peculiar Anglo-American predilection that does not travel well into other cultures' (Stone \& Denham, 2004, p. 2). Analysing the communities of policy specialists in Russian regions, we faced all these conditions: the community is relatively small and is not differentiated a lot by the functions and roles of policy specialists; there are think tanks but policy specialists are not all and not always organized in such organizations, and even if they establish a think tank, it has limited autonomy from the government; political conditions (competition, pluralism, freedoms) usually are not favourable for the development of a complex diversified system of policy advice. Therefore, in Russian regions, we prefer to speak about analytical communities (Belyaeva, 2013).

The focus of this article is the assessment of the policy impact of analytical communities in Russian regions. Analytical communities can be defined as loosely united clusters of professionals doing joint or related work in policy analysis, research and development, who frequently work together on common analytical goals and clients, while not necessarily forming a special organizational structure that differentiates them from think tanks. Examples of analytical communities could be university research departments, regular authors of one analytical journal, members of certain intellectual clubs or regular meetings, informal research groups, including individual intellectuals working together on the regular basis.

The change of research focus from think tanks to analytical communities has some consequences. If for think tanks, we have quite well developed methodology to assess their policy impact, to evaluate the analytical communities' influence, we need to upgrade the research logic and instruments used for think tanks. First of all, we deal with a more amorphous association or loosely united clusters of policy specialists, than those united in a think tank. That is why, to influence policy-making, an analytical community has to be consolidated enough. Autonomy remains a crucial resource for an analytical community but at the individual level: to maintain a certain level of autonomy or not become an individual strategy of each member of the community; organization, where policy analysts work, can be state-dependent, but policy analysts themselves can enjoy a certain level of autonomy in their analysis. If think tank development is determined by mostly political conditions (political freedom, democratic political system, numerous and strong political parties, developed civil society) and some variables that are indicated by the socio-economic development of the country (GDP, population, and number of universities) (McGann\& Johnson, 2006), then to analyse analytical communities, we need to take into consideration a broader context, including culture (Stone \& Denham, 2004).

In this paper, we argue that the policy impact of analytical communities is determined by the level of their consolidation, the autonomy of members of the analytical community, and by the broad contextual factors. We assume that the more consolidated an analytical community is, the more autonomy from the government community members have, and the more favourable the context is (including developed infrastructure, academic culture, global professional integration), then analytical communities are more influential and capable of impacting public policy. Because the methodology to assess think tank policy impact is well developed, we give a brief overview of the research problems related to impact evaluation relevant to analytical community influence assessment as well. Based on these, we propose a research design to assess the policy impact of analytical communities. The research findings and summary support the original assumption about the determinants of the policy impact of analytical communities in Russian regions. In conclusion, a discussion about the possibilities to generalize the results to more cases (Russian regions and countries) is presented. 


\section{THE KEY METHODOLOGICAL PROBLEMS OF THINK TANK POLICY IMPACT ASSESSMENT}

Methods of assessing the influence of think tanks on policy-making differ by indicators, the criteria to define think tanks and answering the questions of who and what to assess (Table 1). The methods evaluate different aspects of policy impact (the prerequisites of policy impact, the possible factors or determinants of policy impact, and proxy parameters). Assessing the think tank policy impact, different authors understand differently the subject of evaluation. The following types of subject of evaluation (what to assess) can be figured out: the position, reputation, influence including the activity in mass-media and parliament, and the impact on strategic planning and policy making (policy impact). Those types are associated with three approaches in political theory to define political leaders, who can govern, have power, and can influence. Those approaches are positional, reputational, and decisional (Ledyaev, 2012). The positional approach defines the political leaders based on their positions or formal status, analysing the resources of political actors. According to the reputational approach, if we want to understand who influences decision-making, we have to study potential leaders' reputation (experts' opinion about opportunities of policy leaders to influence policy making). The decisional method defines political leaders as those actors who directly influence decision-making through their activity: successfully initiate and ensure the adoption of political decisions which are beneficial for them.

The authors who try to assess the policy impact of think tanks (see Table 1), with the exception of Rich (2004), were concentrated on one, maximum two, types of policy impact evaluation (assessing either the position, or the reputation, or the influence). This does not allow them to make conclusions about policy impact as a whole phenomenon. Because policy impact is a multidimensional phenomenon, so its assessment requires in-depth analysis of various groups of indicators. Attempts to combine different types of policy impact evaluation in relation to think tanks in the literature were performed on the qualitative level using case studies. Therefore, the number of think tanks that were analysed reduced to 2-3 cases, that is, loosely sufficient to make general conclusions about the whole industry of think tanks. For example, A. Rich and K. Weaver, in their research conclude that Brooking Institution and Heritage Foundation are the leading American think tanks by their level of visibility in media; by the frequency of their appearances at Congressional hearings and testimonies; by reputation assessment, made by Congress and Washington journalists (Rich \& Weaver, 1998). Also, those two think tanks were actively involved in policy making on such issues as health care reform, policy deliberation on telecommunication, and policy enactment on tax cuts in US (Rich, 2004). But these case studies don't allow us to talk about the influence of other think tanks and analytical communities, the whole think tank industry, nor guarantee that this influence is constant and not a random event. Other solutions are to build up an index or ranking of leading think tanks. McGann's think tank ranking makes generalization about leading think tanks in the country, the region, and even in the world; but these rankings do not show the policy impact of think tanks, because of the reduction of depth of analysis, which can be reached only using qualitative methods, like case studies. Few attempts were made by scholars to establish case studies of think tank policy impact assessment in countries other than Anglo-American cases. In McGann's ranking of countries with the largest number of think tanks in top-10 countries, there are only two authoritarian countries: Russia and China (McGann, 2016). But few case studies were made about the policy impact of Russian and Chinese think tanks.

The same diversity for types of think tank policy impact assessment exists with the indicators of policy impact (Table 1). There are several methodological problems here. First, for policy impact assessment, only a few and not all possible indicators were taken. Second, these indicators are proxy-parameters; they measure policy impact indirectly. That is why they do not always talk directly about the policy impact. For example, the existence of connections between the think tank and the government cannot describe the autonomous influence of think tank on decision-makers, but only the dependence of think tank on the government; or think tanks can be cited a lot by the media not only because they have policy impact, but also as they develop connections and regularly work with the media, or because their attempts to influence decision making failed.

Who assesses? It is usually the author her/himself or external experts (like, journalists and politicians, researchers and think tank personnel, sponsors, donors who finance think tanks). The problem here is to find the balance between different types of information: firstly, opinions of think tank representatives or analysts about themselves (self-declarations); secondly, the assessments of experts and stakeholders who deal with think tanks; and thirdly, statistics, such as budget, visibility in the mass media, the amount of initiatives taken into consideration by decision-makers. Ideally, the researcher has to combine all these sources of information to produce valid results, and verify the received research outcomes by analysing opinions, assessments and statistics comparing the results obtained from one source with the results from another. But because such research design would be too costly, we claim for the researcher to choose at least two out of three above mentioned types of information. 
Tab. 1: Methods of assessing the policy impact of think tanks (TT)

\begin{tabular}{|c|c|c|c|c|c|}
\hline № & Authors & Indicators & Criteria to define TT & Who assesses? & What is a ssessed? \\
\hline 1. & G.W. Domhoff & $\begin{array}{l}\text { 1. Sources of founding } \\
\text { 2. Connection with Power }\end{array}$ & 'importance' of taken position & author & Position (status) \\
\hline 2. & N. Ruble & $\begin{array}{l}\text { 1. Visibility in mass-media } \\
\text { 2. Frequency of appearance } \\
\text { at parliamentary hearings and } \\
\text { testimonies }\end{array}$ & $\begin{array}{l}\text { TT with specialization in economics; } \\
\text { 'Full circle' TT }\end{array}$ & author & Influence (activity) \\
\hline 3. & S. Trimbath & 1. Visibility in mass-media & $\begin{array}{l}\text { World-wide publicity; } \\
\text { TT with specialization in economics; } \\
\text { 'Full circle' TT } \\
\text { Representation of TT of different } \\
\text { political spectrum and geography }\end{array}$ & author & $\begin{array}{l}\text { Influence (activity } \\
\text { in mass-media) }\end{array}$ \\
\hline 4. & J.G. McGann & 1. Expert assessment of reputation & $\begin{array}{l}\text { 'best in the world, region'; } \\
\text { authoritativeness (reputation) } \\
\text { Visibility (citation); } \\
\text { Political autonomy; } \\
\text { Focused on policy impact, and } \\
\text { political influence }\end{array}$ & $\begin{array}{l}\text { Author; } \\
\text { TT Researchers } \\
\text { TT experts } \\
\text { Sponsors } \\
\text { (donors) } \\
\text { Politicians, etc. }\end{array}$ & Reputation \\
\hline 5 & $\begin{array}{l}\text { A. Rich, } \\
\text { R.K. Weaver }\end{array}$ & $\begin{array}{l}\text { 1. Expert assessment of reputation } \\
\text { 2. Visibility in mass-media } \\
\text { 3.Frequency of appearance at } \\
\text { parliamentary hearings and } \\
\text { testimonies }\end{array}$ & $\begin{array}{l}\text { Political autonomy; } \\
\text { Focused on policy impact, and } \\
\text { political influence } \\
\text { Visibility }\end{array}$ & $\begin{array}{l}\text { Author; } \\
\text { Experts } \\
\text { (journalists, } \\
\text { politicians) }\end{array}$ & $\begin{array}{l}\text { Reputation and } \\
\text { Influence }\end{array}$ \\
\hline 6. & A. Rich & $\begin{array}{l}\text { 1. Resources (budget, personnel, } \\
\text { etc.) and strategies } \\
\text { 2. Expert assessment of reputation } \\
\text { 3. Visibility in mass-media } \\
\text { 4. Role in policy making at different } \\
\text { stages of policy process (case } \\
\text { studies) }\end{array}$ & $\begin{array}{l}\text { Political autonomy; } \\
\text { Focused on policy impact, and } \\
\text { political influence }\end{array}$ & $\begin{array}{l}\text { Author; } \\
\text { Experts } \\
\text { (journalists, } \\
\text { politicians) }\end{array}$ & $\begin{array}{l}\text { Position, } \\
\text { reputation, and } \\
\text { influence, and } \\
\text { policy impact }\end{array}$ \\
\hline 7. & D.E. Abelson & $\begin{array}{l}\text { 1. Resources (budget, personnel, } \\
\text { etc.) and strategies } \\
\text { 2. Visibility in mass-media } \\
\text { 3. Frequency of appearance } \\
\text { at parliamentary hearings and } \\
\text { testimonies } \\
\text { 4. Role in policy making at different } \\
\text { stages of policy process (case } \\
\text { studies) }\end{array}$ & $\begin{array}{l}\text { Political autonomy; } \\
\text { Focused on policy impact, and } \\
\text { political influence } \\
\text { Visibility }\end{array}$ & Author & $\begin{array}{l}\text { Position, influence, } \\
\text { and policy impact }\end{array}$ \\
\hline
\end{tabular}

Source: the authors

In the literature, the authors used diverse criteria to define the think tanks whose influence needs to be assessed (Table 1). The authors tried to build and justify an expert sample of think tanks that were chosen for further analysis. The problem here is not only how to build an expert sample of think tanks, but also how do define them, because of the stretching of the concept of think tanks, which always happens when we try to analyse think tanks beyond the USA and Anglo-American tradition.

To avoid these methodological problems, the authors develop a synthetic method to assess the policy impact of analytical communities in Russian regions, in particular, taking into account that in Russian regions, think tanks in the full sense of this notion have not developed. Also, think tanks in Russia now are going through very difficult times, because of the lack of political pluralism and political competition, which are crucial conditions for think tank development (McGann\& Johnson, 2006; Belyaeva, 2013). That is why, we moved the focus of research from think tanks, which still exist in Moscow and work mostly on governmental contracts, to analytical communities, which are larger in quantity and have greater autonomy because they are not limited by a single organization. These may be departments in universities, journals, analytical and intellectual groups, or individual intellectuals. 


\section{RESEARCH DESIGN: PROPOSED METHOD TO ASSESS THE POLICY IMPACT OF ANA- LYTICAL COMMUNITIES}

The proposed method to assess the policy impact of analytical communities in Russian regions is based on the existing methods and includes the following parameters for evaluation: the consolidation of the analytical community, autonomy, authority and activity, influence on policy change, political and cultural context. The central parameter to assess the policy impact is the capacity of the analytical community to influence policy change (analysts' recommendations are taken into consideration and implemented by decision-makers and change the policy in the field, like science, technology and innovation (STI) policy, health care, or migration). Some methods of think tanks' influence assessment measure policy impact directly (Rich, 2004). But those methods lose other important parameters.

Firstly, having the ability to influence policy change requires a certain degree of consolidation of political actors, in this case, the analytical community. Therefore, the basic or primary parameter to evaluate the policy impact of the analytical community is the consolidation of the analytical community. Secondly, the influence on policy change or policy impact is based on autonomy, or the capacity to hold power, which can be evaluated through the analysis of resources, formal status, and the reputation of the analytical community. An advanced and diverse portfolio of resources is necessary for policy analysts, not only to solve the tasks of the client, but also for the permanent implementation of effective analytical activities. Namely, the analytical community should have the capacity to consistently produce objective applied policy analysis despite having a lack of financing (or other resources), dependency on the client and external interventions of third parties. In addition, to address efficiently the policy issue, the analytical community should be active, as well as, autonomous and independent from the interests of other actors. Therefore, for the assessment of the analytical communities' policy impact, it is important to study such parameters as autonomy (including formal status and resource autonomy), authority (including reputation), and activity. Thirdly, the political and cultural context influences the analytical communities' capacity to impact policy change. The context can be favourable or unfavourable for analytical communities. There are diverse contextual factors that can influence the analytical communities' policy impact capacity: political, cultural (e.g., the development of a culture of philanthropy), globalization and others.

The system of these parameters gives the researcher an opportunity to evaluate the policy impact of a collective political actor as a complex phenomenon. Also, there may be a serial association between the parameters: the consolidation of a political actor is a foundation for being an autonomous actor; autonomy based on consolidation is a foundation to influence policy-making (and broader, influence on policy change). Political and cultural factors are contextual for a political actor to impact policy change. See scheme 1 .

Scheme 1: The system of parameters to evaluate the policy impact of a collective political actor.

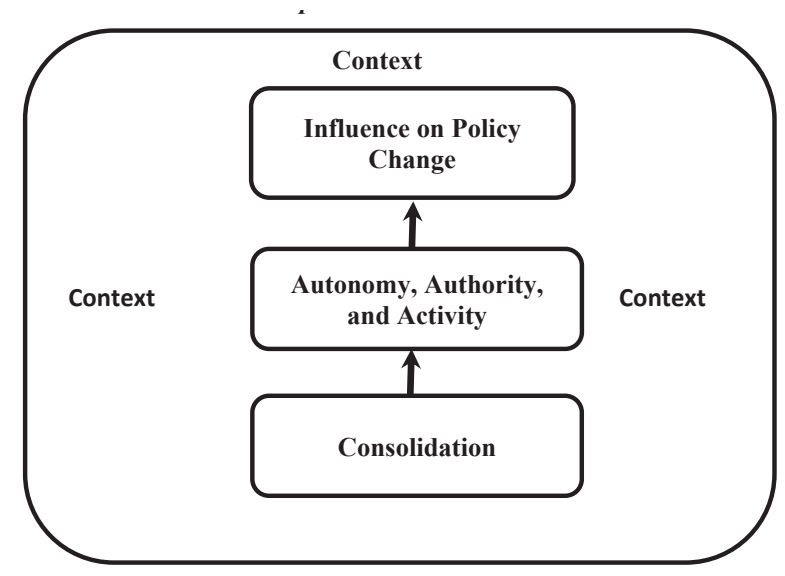

Source: the authors 


\section{Context}

The empirical research of analytical communities in Russian regions was held in 2009-2011. Several workshops and semi-structured interviews with the representatives of regional analytical communities were conducted:

- 19 September 2009 - Workshop with representatives of regional analytical communities in Saratov

- 31 October 2009 - Workshop with representatives of regional analytical communities in Petrozavodsk

- 11 December 2010 - First Workshop with representatives of regional analytical communities in Kazan

- 18 February 2010 - Second Workshop with representatives of regional analytical communities in Kazan

- 27 November 2010 - Workshop with representatives of regional analytical communities (Saratov, Karelia, Tatarstan, Altai) in Moscow

- 2009-2010 - Semi-structured Interviews with representatives of regional analytical communities (Saratov, Karelia, Tatarstan)

- 28 January 2011 - Workshop with representatives of regional analytical communities in Petrozavodsk

First, workshops with representatives of regional analytical communities were held. Then the questionnaire was distributed both to the workshop participants, and those regional policy analysts who had not attended the workshops, but were recommended by the workshop participants as important and reliable members of regional analytical communities. In Table 2, the numbers of both the participants of the workshops and respondents interviewed are presented.

Tab. 2: Numbers of the participants of workshops and interviews

\begin{tabular}{llll}
\hline Region (city-centre of the region) & Workshops participants & Semi-structured Interviews & Total by Regions \\
\hline Saratov oblast' (Saratov) & 18 & 25 & 43 \\
\hline Karelia (Petrozavodsk) & 30 & 20 & 50 \\
\hline Tatarstan (Kazan') & 20 & 8 & 28 \\
\hline Total for Regions & 68 & 53 & 121 \\
\hline
\end{tabular}

Source: the authors

Karelia, Saratov and Tatarstan were selected for this research because of several reasons. Common to all three regions is openness to national and even to international political life, and strong academic communities. Analysts of all three regions are involved in national policy-making through conducting applied projects for federal government on a contract basis. Saratov region was famous for its first democratically elected governor Dmitry Ayatskov, who held a very active position at federal level; till now the level of political pluralism and media independence in Saratov region is very high, like in Karelia (Petrov \& Titkov, 2013). Karelia and Tatarstan have close relations with other countries: the Scandinavian countries, especially Finland, and Turkey, respectively. Also, analysts of all three regions are involved in global professional networks (Belyaeva, 2013). Strong academic traditions are supported by university and academic centres of national importance such as Kazan Federal University in Tatarstan, Saratov National Research University, and the Karelian Research Centre of the Russian Academy of Sciences. All these allowed us to assume that analytical communities in those regions have high policy impact.

Differences of the selected regions are equally important. These differences allowed us to define Karelia, Tatarstan, and Saratov as three diverse models of analytical community policy impact. These three different models may be relevant for other Russian regions as well.

The Republic of Karelia is a border region at the north-western part of Russia such as Kaliningrad, Murmansk, Archangelsk, Vologda, Pskov, Leningrad regions, Komi republic, Nenets district, and Saint-Petersburg. These regions are a part of the EU project 'the Northern Dimension', which aims to develop social and economic cooperation in Northern Europe. The political regime in Karelia, by the experts, was defined as 'modest competition based on rules' (Titkov et al., 2013a). Along with other north-western regions, with little exceptions, the Republic of Karelia is one of the leading democratic regions, in the top- 25 out of 82 Russian 
regions (Petrov \& Titkov, 2013). The Republic of Karelia is a multi-ethnic region with a dominance of Russians in the population, which makes Karelia a model region also for ethnic policy development.

Tatarstan is on the opposite side of the spectrum of Russian regions compared with Karelia but could be viewed as a model region for national republics of Russia. Tatarstan has a long history of struggle for its autonomy from central authority, and contrary to the violent model of Chechnya, was capable of developing a peaceful model of autonomisation, which still remains an example for other national republics. Authoritarian nature of a political regime, stable economic growth, and balanced ethnic policy between the majority of Tatars (53\% of the population) and significant number of Russians (40\%) inspired experts to define the model of Tatarstan as 'effective East Asian capitalism' (Titkov et al., 2013b).

Saratov Oblast is a middle region of Russia based on many indicators of socio-economic development. The political regime is defined as 'fight without rules' (Titkov et al., 2013c), where the absence of democratic institutions makes political competition unpredictable; when in a plural environment, several autonomous political actors exist, unlimited by any rules; rules are created by actors temporarily, dependent upon the situation. These peculiarities make Saratov region an exemplary case for other Russian regions with similar contexts.

The bases for data analysis were the results of semi-structured interviews with representatives of regional analytical communities. Descriptive statistics of the answers of respondents are presented in the research findings: individual answers were calculated in percentages of respondents and where possible in average scores by regions, comparison of percentages of respondents and average scores allow us to trace similarities and differences between regional analytical communities by indicators. T-test was used to identify significant differences between averages. ${ }^{2}$ Descriptive statistics are interpreted according to the results of analysis of the transcripts of workshops, the authors' observations, and the assessments of experts. Also, answers on open-questions are used to interpret the quantitative results of the interviews. The received findings were cross-checked by comparing the results received from different sources (interviews, workshops, observations, and experts' assessments), close-ended and open-ended answers to questions within the interviews.

Nevertheless, these empirical data have some limitations, which have to be taken into consideration to better grasp the research findings. Firstly, these data are opinions and declarations of representatives of analytical communities about themselves. That is why the numbers presented below are interpreted according to the authors' additional observations, and consultations with experts (research coordinators in the regions and specialists on Russian regions). In each region, there were research coordinators, ${ }^{3}$ always the representative of regional analytical community, but with an organizational capacity to mobilize other representatives of the regional analytical community who can contribute in the research, such as by attending workshops or filling in the questionnaire. Also, we consult with the specialists in Russian regions, A. Titkov, ${ }^{4}$ M. Mamonov, ${ }^{5}$ and O. Reut. ${ }^{6}$ Secondly, we do not deal with a random sample. That means that we cannot generalize numbers presented below to the analytical communities at large (e.g., we cannot make conclusions about the analytical communities in Saratov based only on the results of the interviews of Saratov analytical communities' representatives). The proposed sample is not representative. What follows is that the statistical data are valid only for those with whom the interviews were conducted. Those respondents were devoted to the research goal to evaluate the regional analytical communities' role (power, influence and impact), were reflecting on these topics, are interested in increasing this role; are more active, compared with those policy analysts who did not participate in the research, with an active position to influence policy change in the region. However, these limitations do not reduce the significance of findings, because, authors interpret the data based

2 The two-sample T-test with unequal variances was used, where $\mathrm{P}(\mathrm{T}<=\mathrm{t})$ two-tail $<0.05$.

3 Research coordinators in the regions:

In Saratov oblast': M. Mamonov - first Deputy Minister of Information and Press, the Government of the Saratov region (1998-2005), the head of the Centre of Information Projects, Associate Professor of Political Science, Volga Region Academy of Public Administration in Saratov (2005-2010), head of research projects in All-Russian Centre of Public Opinion (WCIOM) in Moscow (from 2010); A. Zabbarov, Volga Region Academy of Public Administration in Saratov, Saratov Socio-economic Institute.

In Karelia: A. Titov - the President of the Karelian Research Centre of the Russian Academy of Sciences, A. Sukhorukov - Chairman of the Board of Fund of support of innovative projects 'New dimension', Petrozavodsk State University; O. Reut - Karelian Research Centre of the Russian Academy of Sciences, Member of the Expert Council of the Centre of Internet Policy at Moscow State University of International Relation (MGIMO)

In Tatarstan: A. Salagaev, S. Sergeev - Kazan National Research Technological University; O. Zaznaev, S. Shayhitdinova - Kazan Federal University

4 National Research University Higher School of Economics, see more here https://www.hse.ru/en/org/persons/67574

5 See link 3

6 See link 3 
on additional information (workshops, authors' observations, and consultations with experts), and test the conclusions by comparing findings received with different indicators, which verify each other.

\section{RESEARCH FINDINGS}

\section{Context}

There are four types of contextual factors important for the formation and development of analytical communities (Belyaeva, 2013): Infrastructure for analytical communities (existence of structures, centres, spaces, informal groups that organize individual analysts into some organizational forms; analysts who can be viewed as 'strategic actors' (Fligstein, 1997); human resources for policy and analytical work, revolving door system between academy, government, business); Factors of political context (level of civil society development, political competition and pluralism, development of democratic institutions, institutionalisation, openness and transparency of political processes; capacity of analysts to build coalitions with other policy actors); Factors of cultural context (development of philanthropy traditions, tradition of endowment, sponsorship and broader context connected with the type of political system and even type of civilisation); Factors of globalisation (inclusion of analysts into global ideational market, professional mobility of analysts, including academic mobility, inclusion into the activities of international professional academic associations, high level of world-wide citations, participation in international conferences, use of professional methods, techniques and technologies, other sorts of professional collaborations across national borders).

The most important factors for assessing the analytical communities' capacity to have an impact on policy making are the political conditions - more precisely, the level of political competition and pluralism and the level of democratic institutionalisation of decision-making in the region. Interviewed analysts, in general, think that political context is not very favourable for their work and as a result for policy impact. The t-test showed that the differences between the averages for each region are not statistically significant, as shown in Diagram 1. Authors' observations and consultations with experts (specialists on Russian regions and analytical communities in those regions) give additional information for interpretation. It appeared that the more favourable situation with political pluralism and democratic institutionalisation is in Karelia, less in Saratov, worst in Tatarstan.

\section{Diagram 1.}

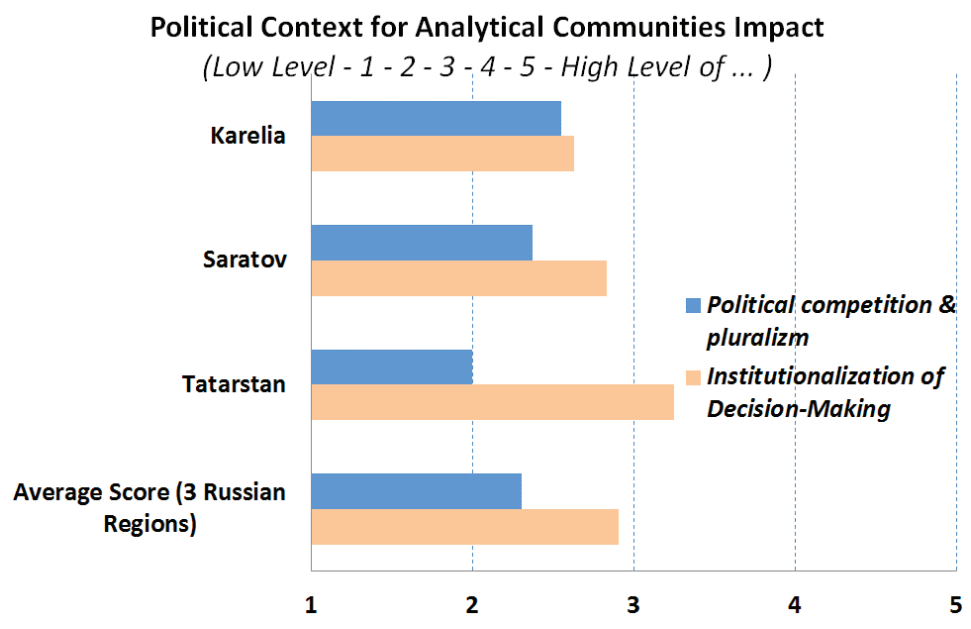

Source: the authors

Because of a variety of factors that have an influence on the capacity of analytical communities to impact policy change, for each polity (nation state, region, municipality) a unique combination of factors can be identified, which frame the specific political environment and context. Based on the observations of analytical communities at the federal level - Moscow (Zaytsev 
2010), and at regional level - Saratov region, Karelia and Tatarstan - we can identify the combination of factors favourable for the development of analytical communities. Despite the difference between the contexts in Moscow, Saratov, Karelia, and Tatarstan, there are communalities: legal prerequisites (liberal legislation about NGO's) and philanthropy traditions and practices are very week. Karelia and Tatarstan are at two different poles. Central to their polarisation is the level of political competition. In Karelia, the legislative assembly of the region is represented by more than one party, which is normal for Karelia (currently represented by five parties, including 'Yabloko', the opposition political party to President Putin). For Tatarstan, the political competition has never been the norm (currently in regional legislature, two parties are represented, with the vast majority from the pro-Putin political party 'United Russia'). In Saratov Oblast, there are three political parties in the regional legislature, with the majority being the proPutin political party 'United Russia'. In Karelia, a high level of political competition allows the analysts to discuss different strategies and public policies to implement different choices of policy alternatives. Therefore, for social issues and problems, different policy alternatives are proposed; this allows several platforms for discussion, where diverse interest groups can participate, which in turn produces a more or less coherent strategy. So, the pluralism certainly helps.

We see a huge difference between Karelia and Tatarstan, where the political context is dominated by one authority, which sets strategies for all. Analytical communities have to work with the authorities, those who do not include the vertical of power, proposing alternatives are just marginalised. On the one hand, this gives consolidation to pro-governmental analysts, on the other - very little choice increases the risk of mistakes because there is no market of ideas as analytics support all government decisions. There is no space for discussion.

In Karelia, there is more political competition and pluralism, which lead to more discussion on such important policy issues as educational reforms, transparency and development of regional budget processes, economy of tourism, culture development and local ethnic cultures' support (Suhorukov, 2011). These important issues are a special concern of the government, which gives contracts to regional analytical communities to develop the strategies of regional and policy development. There is competition not only between different political parties, but also between different regional analytical communities that propose different alternative strategies for one policy issue. The competition is reasonable, based on the communication between analysts. For example, when the policy strategy for the whole region was developed; analytical communities were united to develop the strategy and each analytical community found itself some niche.

On the other hand, Saratov has less political competition than Karelia, because despite the fact that there are a lot of analytical communities and more than one political party, there is no cooperation between diverse political actors. There is a conflict, or more precisely 'the war of all against all'. In this situation, effective strategic planning and policy making is impossible. Both situations are bad for analytical communities' capacity to influence policy making: excessive consolidation and merging between authority and analytical communities (like in Tatarstan), and when there is a conflict and confrontation between different political actors, where analysts have to serve their political patron's interests (like in Saratov).

As for the development of democratic institutions, which can give more competition by rules, and absorb confrontation into more civilized practices of public deliberation, the situation in Tatarstan is similar to Moscow and Saratov, where this factor is unfavourable. There are fewer opportunities to build coalitions with other actors, as well as the low level of openness of the political system. This negates seemingly more favourable conditions in Moscow and Saratov, compared with Tatarstan, in terms of political competition. Political competition in Moscow and Saratov is not backed by democratic institutions, which allows coordinating diverse interests, opportunities to build coalitions between different actors, the open nature of the political process. These do not guarantee the effective policy impact of the analytical communities on decision making, despite the well-developed infrastructure for analytical communities, the presence of the well-known leaders of the analytical community, and high level of the mobility of analysts between sectors (Zaytsev, 2012).

\section{Consolidation of analytical communities}

We assessed the consolidation of regional analytical communities by asking the question about the 'Frequency of their participation in other analytical structures and events' (Diagram 2). Regional analytical communities occasionally participate in the work of other analytical structures and events (seminars, workshops). The frequency of communications between analysts varies from rare connections to contacts from time to time. A statistical test did not show any statistically significant differences between average scores by regions observed in Diagram 2. But nevertheless, we can assume that the regions differ and we can rank our regions in association 
with their analytical communities' level of communication connectivity (and broader-level of consolidation) from high level to low level as follow: Karelia (high), Saratov (medium), and Tatarstan (low).

\section{Diagram 2.}

Frequency of participation in other structures and events? (1 - Not participate, 2 - Rarely, 3 - from time to time, 4 - Often)



Source: the authors

This assumption is proved by the analysis of the answers to an open question: Are there any problems on interaction between analytical communities and analysts within the region? If yes, what are they? After analysing the responses to this question, we can conclude that in Karelia, we can observe the formed analytical community that exists, of course, not without problems, but there are problems of a different level than in Saratov and Tatarstan. Analysts said about 'weakness of unifying force', insufficient trust to each other, absence of 'a common vector' and coordinating centre, low awareness of public interest. The discourse about such issues rather suggests that the community was formed, but they are facing difficulties in further consolidation.

The opposite situation is observed in Tatarstan, where not only the consolidation of analytical communities is questioned, but also the existence of independent analysts is under question too. Analytical communities are fragmented, consisting of separate communities and analysts. Several problems were noted: the lack of channels of communication, lack of demand of analytical work, lack of professionalism, politicization, political bias and even corruption of analysts.

Saratov again takes an intermediate position between the two poles. Here the problems of Tatarstan analysts (political bias) are combined with the problems of Karelian communities (lack of coherence, and coordination). However, in Saratov, these problems accumulate specific challenges that hinder the formation of a unified analytical community and its consolidation: affiliation with political structures, building patron-client relations and competition, and as a consequence, dependence on the political sponsor or patron, which competes with other political actors - sponsors of other analytical communities.

\section{Assessing the qualities of autonomy, authority, and activity}

The first step to evaluate political autonomy and authority is to have a look at the formal status or position, which in our case the actor, representatives of analytical communities have. The actor's formal position or status can be viewed as an important resource for the analyst if he/she takes a high-ranking position in the political hierarchy. But it is rare for representatives of analytical communities. Another opportunity to collect enough resources and establish political power for analysts is to have several formal positions (use the strategy of diversification). These indicators of political influence are presented in Diagrams 3 and 4 . The interviewed Russian regional analysts prefer the status of being a member of academic institutions, which traditionally in Russia do not have high ranks in the 
political hierarchy. One exception is the analytical communities in Saratov, whose representatives prefer holding the formal position of the members of regional authorities.

\section{Diagram 3.}

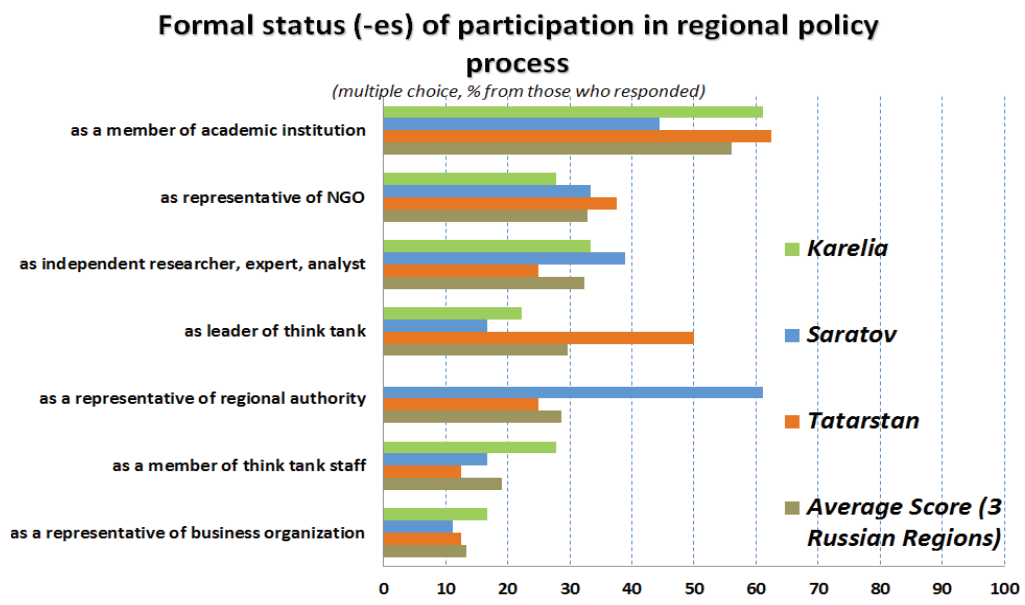

Source: the authors

Analysts in Saratov and Tatarstan frequently (more than the middle 3 score) use different formal statuses (about 4 different statuses). Analysts in Karelia frequently asked the status of the independent researcher, expert and analyst. Statistically significant differences were found between Karelia and Saratov by parameter being a representative of regional authority and as in the cases of Karelia and Tatarstan by parameter: being a leader of think tanks.

Diagram 4.

Preference of participation in specific status (es)

(Low - 1 - 2 - 3-4 - 5- High)

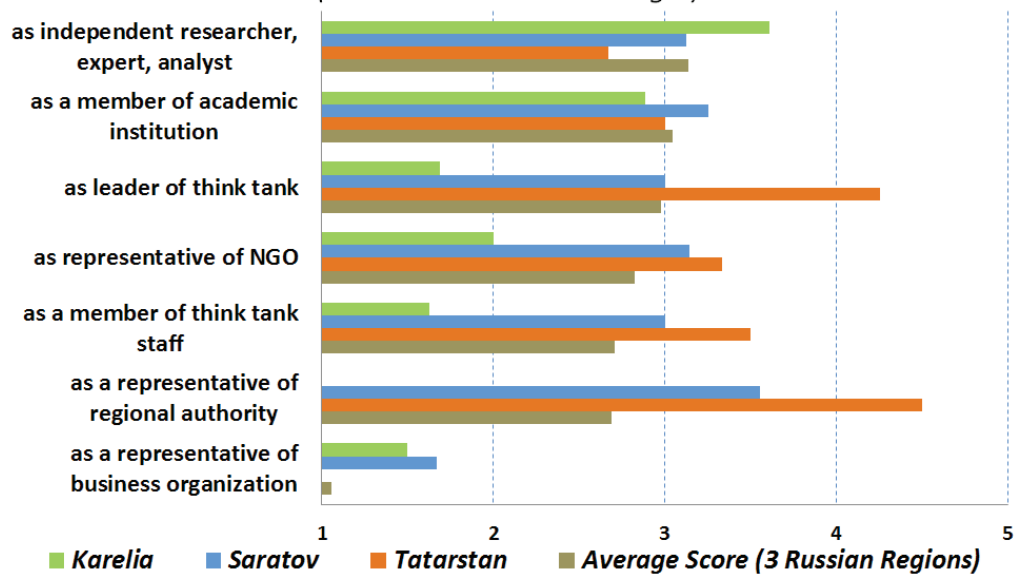

Source: the authors 
This should be interpreted as a very intimate connection between the analytical communities in Saratov and Tatarstan with regional authorities in those regions (analysts simultaneously hold positions in regional authorities). This does not mean that analytical communities of Saratov and Tatarstan can make an impact on their regional authorities but, rather, the other way around that authorities in these regions have very strong influence on those analytical communities in the format of patron-client relationships. This finding is corresponding with declared problems of analytical communities. While in Karelia the situation is different, their analytical communities are more independent, they have their own agendas and they can provide independent analysis to their regional authorities. Tatarstan differs from Karelia by popularity of such analysts'status as think tank's leaders. Possibly, the creation of a think tank makes it easier to be embedded in the patron-client relations with the authorities.

Intellectual resources have been measured by Frequency of release of analytical product by the analytical communities. We cannot say that there is one type of analytical product that is often issued by the analytical communities in the regions. Despite statistically significant differences not being recorded, in general, the activity of the analytical community to produce different types of analytical products is on an average level and below average. The most common forms of intellectual products of regional analytical communities are the analytical reports, papers for decision-makers, political parties, and politicians. That says that, indeed, we have the community of analysts in the field of public policy, not consultants or experts. ${ }^{7}$

\section{Diagram 5.}

\section{Frequency of release of analytical products}

$(0$ - no answer/not issue, 1 - very rarely, 2 - rarely (once a year), 3 - from time to time (several times a year), 4 - often (several times a quarter), 5 - very often (several times a month))

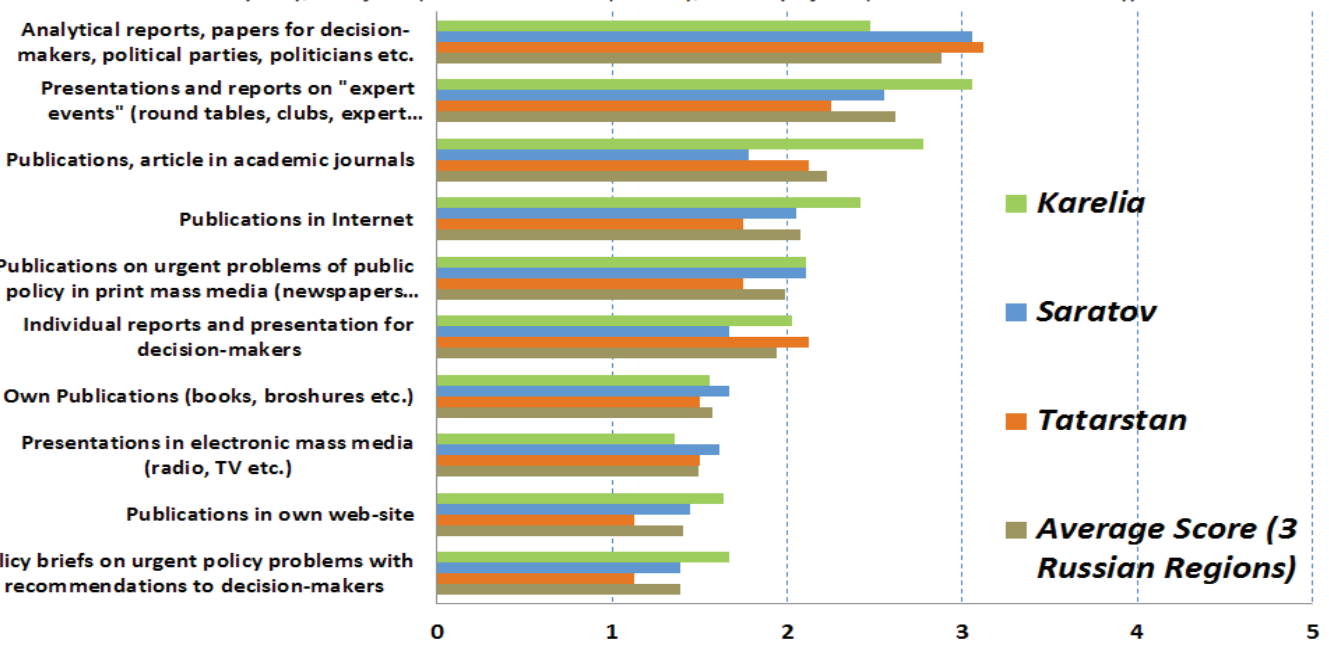

Source: the authors

To define the importance of a resource portfolio of analytical communities we need to evaluate their social capital or the resource of connections. To evaluate it, we would use specific indicators: frequency of connections between analytical communities and decision-makers; the target groups that the analytical communities want to influence and their claimed experience in different sectors of the society: government, business, NGO's, media and academia. The regional analytical community is often in contact with politicians, officials and journalists (Table 3). Statistically significant differences between regions were recorded in contacts with the media - in Tatarstan and Saratov analysts most often in contact with journalists, in Karelia, on the contrary, it is not the most common channel of communication for analysts. The above revealed a dependent position of analysts in Saratov and particularly in

7 About the difference between analysts, experts, and consultants, please, see Zaytsev (2012) 
Kazan from decision-makers; we can assume that widespread contacts with the media in these regions is due to the performance by the analysts' legitimisation of decisions taken by the regional authorities.

Tab. 3: Please, assess the frequency, with which you (analytical structure that you lead) contact with decision-makers. For assessment, please, use 5-grades-scale.*

\begin{tabular}{lllll}
\hline$:$ & Karelia & Saratov & Tatarstan & $\begin{array}{l}\text { Average Score } \\
\text { (3 Russian Regions) }\end{array}$ \\
\hline With politicians and regional state officials, you personally know. & 3,3 & 3,7 & 3,7 & $\mathbf{3 , 6}$ \\
\hline With journalists and mass-media representatives. & $\mathbf{2 , 5}$ & $\mathbf{3 , 7}$ & $\mathbf{4 , 1}$ & $\mathbf{3 , 5}$ \\
\hline With political party representatives. & 2,3 & 2,6 & 2,7 & 2,5 \\
\hline With members of parliament (deputies, and public servants in parliament) & 2,5 & 2,9 & 2,8 & 2,7 \\
\hline With regional state officials of regional administrations, ministries. & 3,1 & 3,6 & 3,5 & $\mathbf{3 , 4}$ \\
\hline With top-management of large corporations. & $\mathbf{1 , 8}$ & $\mathbf{1 , 7}$ & 2,0 & $\mathbf{1 , 8}$ \\
\hline With representatives of NGO's. & 3,1 & 2,9 & 2,5 & 2,8 \\
\hline
\end{tabular}

* Statistically different results in averages, based on $T$-test, is bold

Source: the authors

Political orientation of analytical communities of Tatarstan and Saratov is confirmed by the analysis of the analysts' responses about target groups on which they focus (Table 4). Regional and local administrations are the target groups for all three communities. For Karelian analysts, the more relevant target groups are regional legislature (which is not surprising, since, as mentioned above, there exists a real competition between the different political forces) and NGO's, which is relatively stronger in the Republic of Karelia. In Saratov, the political parties act as coordination centres for analysts - analysts gathering around the clubs at the political parties, which is reflected in the popularity of this target group for analysts of Saratov. It is also interesting that analysts of Karelia consider federal authorities as their target audience. Indeed, during the workshops, the analysts of Karelia reported that they receive contract work from the federal government; hence, the analytical communities of Karelia successfully compete with Moscow analysts.

Tab. 4: Which target groups you / your analytical centre is mostly oriented (multiple choice question, \%)

\begin{tabular}{lllll}
\hline & Karelia & Saratov & Tatarstan & $\begin{array}{l}\text { Average Score } \\
\text { (3 Russian Regions) }\end{array}$ \\
\hline Mass media structures. & 45 & 76 & 88 & 70 \\
\hline Regional administration. & 75 & 68 & 50 & 64 \\
\hline Local administration. & 75 & 48 & 50 & 58 \\
\hline Regional legislature. & 75 & 52 & 13 & 47 \\
\hline NGO's. & 60 & 40 & 38 & 46 \\
\hline Political organizations and parties. & 35 & 52 & 38 & 42 \\
\hline Business-oriented structures. & 40 & 36 & 25 & 34 \\
\hline Other analytical structures, PR agencies. & 10 & 32 & 38 & 27 \\
\hline Federal administrations. & 40 & 32 & 0 & 24 \\
\hline Federal legislation. & 40 & 24 & 0 & 21 \\
\hline Federal judiciary. & 15 & 8 & 13 & 12 \\
\hline
\end{tabular}

Source: the authors 
Next table is showing the responses to the following question: Do you have experience of work with government, business structures, $N G O$ 's, media structures, academic structures? (Multiple choice question, Table 5). What we see from the table is that the experience of analytical communities of Tatarstan and Saratov are mostly connected with government, which supports the previous hypothesis of a close connection between them, which is now being demonstrated through resource of connections or social capital. On the other hand, analytical communities of Karelia differ, because their target groups are much more differentiated and they have experience of working in spheres that do not directly depend on the government - academic structures and non-governmental organizations.

Tab. 5: Do you have experience of work with government, business structures, NGOs, media structures, academic structures? (Multiple choice question, \%).

\begin{tabular}{lllll}
\hline & Karelia & Saratov & Tatarstan & $\begin{array}{l}\text { Average Score } \\
\text { (3 Russian Regions) }\end{array}$ \\
\hline Government. & 35 & 72 & 63 & 57 \\
\hline Business structures. & 45 & 40 & 13 & 33 \\
\hline NGO's. & 75 & 40 & 13 & 43 \\
\hline Media structures. & 20 & 36 & 38 & 31 \\
\hline Academic structures. & 80 & 48 & 38 & 55 \\
\hline
\end{tabular}

Source: the authors

In general, the social capital of analytical communities of Karelia is quite diverse. In Saratov and Tatarstan, the social connections are subordinated to the main purpose - keeping patron-client relationship of analysts with the government. The next type of analytical community resource is transparency. To evaluate the level of transparency of regional analytical communities, their representatives were asked: Please, assess the percentage of your analytical products open for the public to all of your applied research made in the last year. The percent of such work open for public viewing (according to the respondent's assessments) in Karelia - 73\%, in Saratov - 39\%, in Tatarstan - 31\%.

Organizational resource is an important part of the resource portfolio of analytical communities (Table 6). These indicators are: number of the staff in the organizational structure that they represent, number of people related to their immediate place of work from the wider analytical community (that they can easily invite for the implementation of the research project if they have a policy analysis request). We summarized the responses to those questions in the table given below.

Tab. 6:

\begin{tabular}{|c|c|c|c|c|}
\hline & Karelia & Saratov & Tatarstan & $\begin{array}{l}\text { Average Score } \\
\text { (3 Russian Regions) }\end{array}$ \\
\hline $\begin{array}{l}\text { How many staff are currently employed in the analytical structure that you } \\
\text { represent? }\end{array}$ & 25 & 8 & 13 & 15 \\
\hline $\begin{array}{l}\text { How many colleagues can you quickly involve in an analytical research task to } \\
\text { implement a particular project? }\end{array}$ & 13 & 10 & 56 & 26 \\
\hline
\end{tabular}

* Statistically different results in averages, based on T-test, is bold

Source: the authors

Personnel resource is another component of the resource portfolio of analytical communities, which we define by two basic indicators: average age of regular employees and close co-operators within the analytical community, their academic qualification the number of PhD holders, both candidate and doctor of science. (Table7). The data provided through the questionnaires filled by analytical community members presented in the table below allows us to know that in all three regions, the average age of people 
regularly employed within the analytical communities are between 30-40 years old, which corresponds to the most productive age of professional activity. But statistical test shows that the analysts in Tatarstan are on an average younger than their colleagues in Karelia and Saratov.

The level of academic qualification significantly differs, while in Tatarstan, there are only 2, in Saratov only 4 and in Karelia, it has risen 3 times more to the level of 16 members of the community with PhD's. Karelian analytical communities have close connections with universities and the academy of sciences, built on strong academic traditions within the Karelian analytical communities; most of their structures exist within several strong universities in Petrozavodsk, as well as the Karelian Research Centre of Russian Academy of Science. While in Tatarstan and Saratov, the professional background of analysts is more often connected to media work, public relation activities, and government civil servants, which demands younger professionals.

Tab. 7:

\begin{tabular}{lllll}
\hline & Karelia & Saratov & Tatarstan & $\begin{array}{l}\text { Average Score } \\
\text { (3 Russian Regions) }\end{array}$ \\
\hline What is the average age of the colleagues in your analytical structure? & 39 & 37 & $\mathbf{3 1}$ & 36 \\
\hline How many colleagues have PhD or higher academic qualification? & $\mathbf{1 5}$ & 4 & 2 & 7 \\
\hline
\end{tabular}

* Statistically different results in averages, based on T-test, is bold

Source: the authors

In addition to the positions and resources, an important element of analytical communities' capacity to influence public policy is the active participation in various forms of political activity (such as participation in the work of government bodies, parliamentary hearings, government commissions, various discussion platforms, contract work, interviews in the media) (Diagram 6). Regional analytical communities are not often involved in the proposed forms of political activity. The most popular forms are involvement in the advisory, consultative governmental bodies and discussion events (workshops, clubs, etc.). Statistically significant differences between regional analytical communities were not found. However, the opinions collected during the workshops and the findings discussed above allow us to conclude that analysts of Tatarstan participate more in the work of consultative and advisory structures at regional authority level, while the Karelian analytical community prefer to participate in discussion events (like workshops, clubs, expert seminars, etc.).

Summarizing this part, the analytical communities in Karelia have a much wider portfolio of resources and more academic autonomy that is based on the long lasting respect to academic work in Karelia. This status is also based on diverse academic communities and several strong academic centres, wide diversity of the citizen's organizations and NGO's that allow them to have different analytical agendas. Those analytical agendas are supported by diverse political actors that are providing political pluralism, which is also providing different business and founding opportunities both from the regional and federal agencies.

Analytical communities of Saratov and Tatarstan are closely connected with power that makes individual analysts dependent on the government (in one centre of power for Tatarstan, in several centres of power for Saratov). It makes analytical communities follow the research agendas provided by governmental actors and does not allow them to develop any significant alternatives. Limited communication strategies and organizational resources, selection in analytical structures based on personnel loyalty to patrons, make the analysts' activity unavailable to the public. Their research capacities are limited and results of this work is predictable, which make them quite weak for the goals of strategic planning and policy making, as it is demanding the analysis of alternatives. 
Diagram 6.

\section{Forms of analytical activity}

(0- no answer/not praticipate, 1 - very rarely, 2 -rarely (once a year), 3 -from time to time (several times a year), 4 -often (several times a quarter), 5 - very often (several times a month)

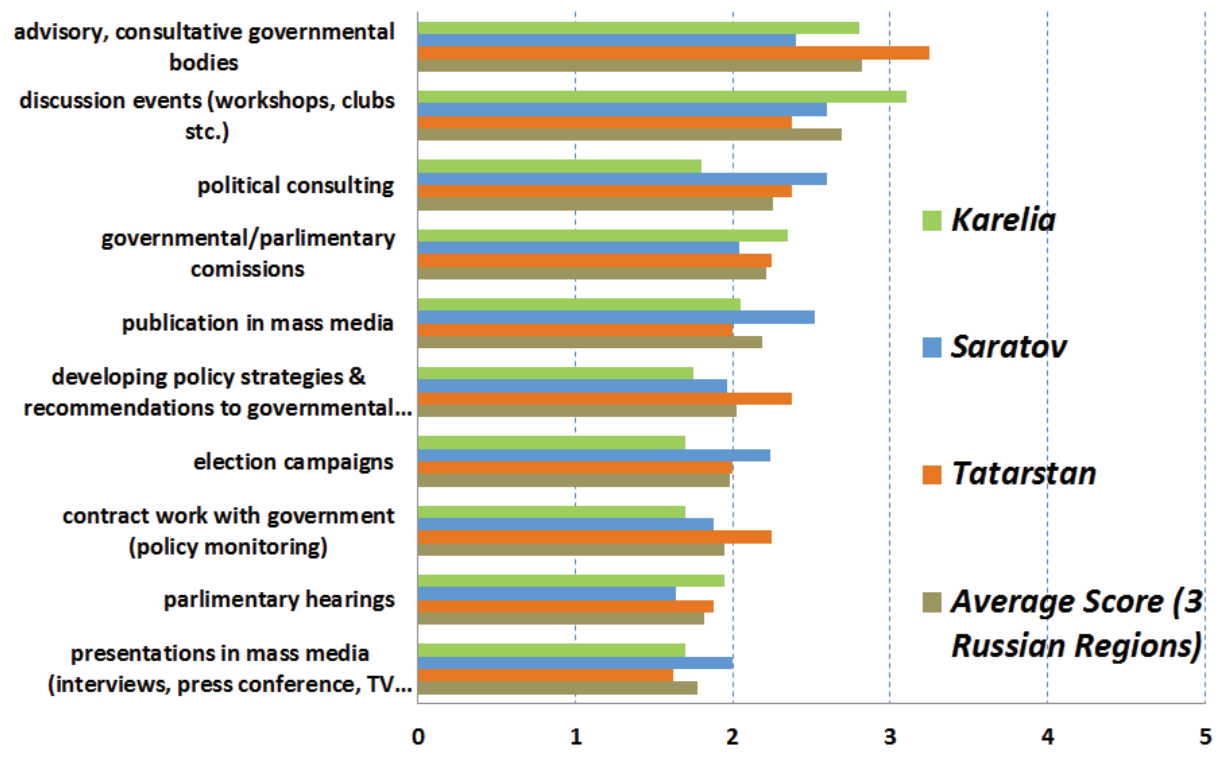

Source: the authors

\section{Evaluating capacity to influence on policy change}

On the open-ended question: Do you hand in your research specific recommendations for decision makers? - the analysts of Karelia and Saratov responded positively. At the same time, there are different motivations to give recommendations - from 'it is client's requirement' to 'influence on policy change'. In Tatarstan, the analysts are not so sure of the need to make recommendations to the decision-makers; there is even an opinion that 'it is not the task of the analysts'.

Also, the question was asked: Have you undertaken any special effort to ensure that your recommendations (research) have reached the desired destination, to take effect? What kind of effects? In the regions, many analysts finished their activity at the stage of recommendation proposal and did not make any further efforts. But few applied a fairly diverse arsenal of efforts.

In Karelia they are: the manifestation of their own initiative for the preparation of analytical reports to the state authorities; use a variety of platforms (regardless of their political and ideological bias) and dissemination of newsletters, publications; personal contacts; media publications; emails petitions to regional authorities; bringing an obligatory position to the 'most important' decision maker; speaking directly to the 'most important' decision maker; use in the classroom, education; training seminars on specific issues; speaking at government meetings, meetings of committees in the legislature. In Saratov, such efforts were less diverse: repetition, clarifying the position to the 'most important' decision maker, forcing a counter-statement, analysis, clear statement of the negative consequences of a negative decision; presentation of recommendations by the ad hoc meetings, consultations; through the clarification of materials provided and arguments to the client; appeals to the governor, the regional legislature. In Tatarstan, the efforts were slim: the actions through the 'bureaucratic machinery'; making interesting analytical product through design, language; publications in media. Furthermore, the opinion was expressed that taking any efforts to promote their recommendations for analysts was simply useless.

When analysts were asked that in which spheres of policy making, they had made real influence, the responses were as follows: in Karelia, the analytical community had real influence on regional strategic planning directly participating in formulating different regional strategies of development, that were publicly presented and discussed and after discussion, were adopted and became regional laws. They also had deep influence on formulating economic policy, tourism development, ethno-national policy, territorial planning, and local self-governance, cultural policy, and migration policy in the Republic of Karelia. In comparison to Saratov Oblast, almost all 
the examples of real influence that were not numerous, dealt with the formulation of information policy, $P R$, and electoral campaigns. In Tatarstan, the examples of political influence of analytical communities were even less evident, but there was one particular field in which the contribution of analytical communities was valued by the regional administration: it was the creation of electronic government. Though it is important to mention that in the projects concerning electronic government, the only analytical structures that allow participation and have government contracts, are those which are directly related to the power structures and are often 'in-house' analytical centres made by the government civil servants.

Tab. 8: Please, provide several examples on which exact projects you were working on in your capacity as political analysts, where the results of your analytical work were implemented in the policy making process.

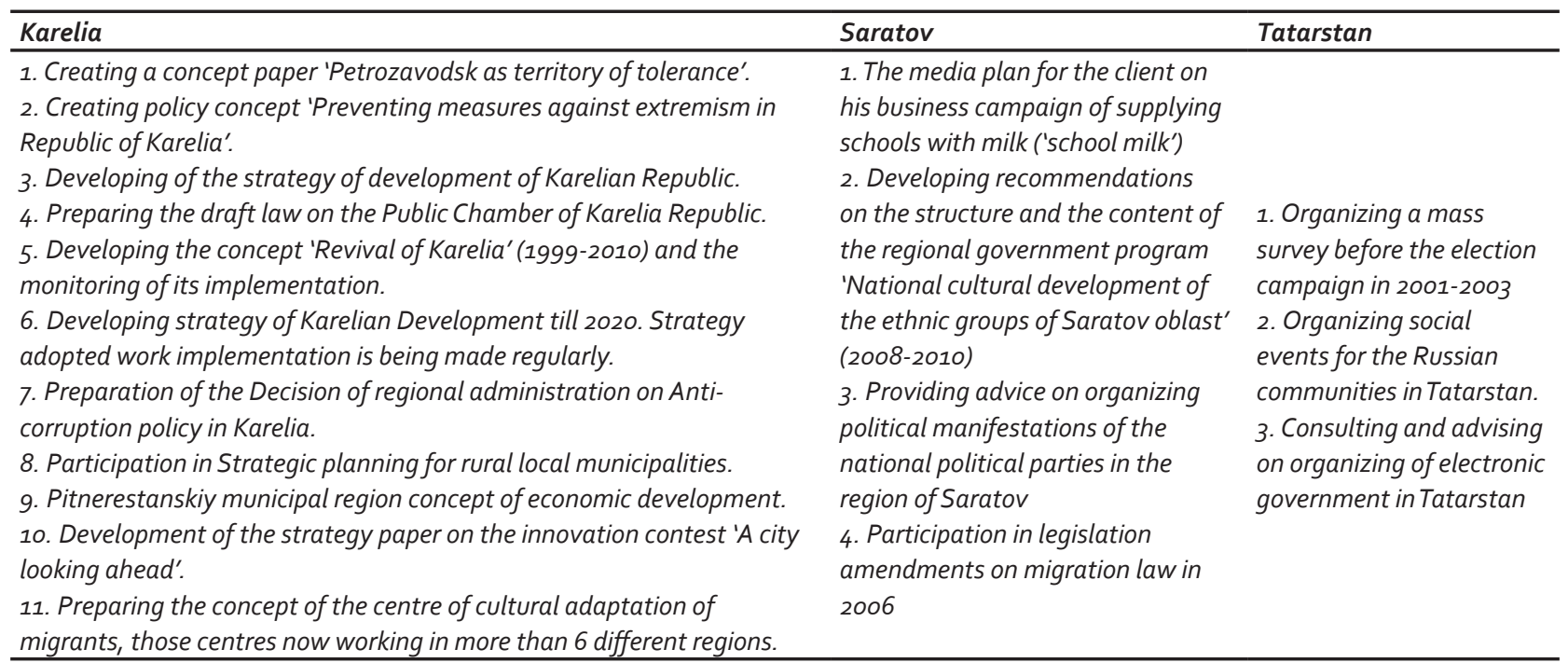

Source: the authors

To add quantitative assessment to the qualitative picture described above, regional analysts were asked an additional question: Which percentage of policy recommendations that you have proposed had been accepted by decision-makers and implemented into regional policies? The following is the diagram response to this question. As we see from this data, on an average $40 \%$ of recommendations were implemented, which could be seen as a high efficiency.

\section{Diagram 7:}

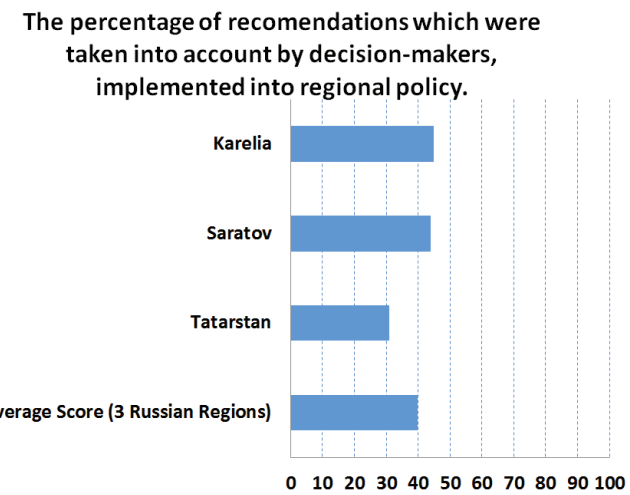

Source: the authors 
In this picture, Tatarstan looks more modest (but this is not proven by statistical analysis, which showed that differences here are not significant). Nevertheless, $31 \%$ of accepted recommendations could be regarded as quite a high policy impact, which does not differ much from $44 \%$ and $45 \%$ of those recommendations that had been accepted in Saratov and Karelia. In Saratov and Tatarstan, where the analytical communities are dependent on power, their self-assessments of the capacity to influence on policy change independently is exaggerated, because in these 2 regions, the analysts are mostly doing something that had been pre-requested from them by power structures.

\section{Summary evaluation of policy impact}

Diagram 8 summarizes the analysis of policy impact of analytical communities in three Russian regions: the Republic of Karelia, the Saratov region and the Republic of Tatarstan. We estimate the four general parameters of the original research design to assess the policy impact. Numerical scores were assigned by the authors of this article, based on the above analysis, using a five-point scale.

Diagram 8: The Evaluation of Policy Impact of Analytical Communities in Three Russian regions.

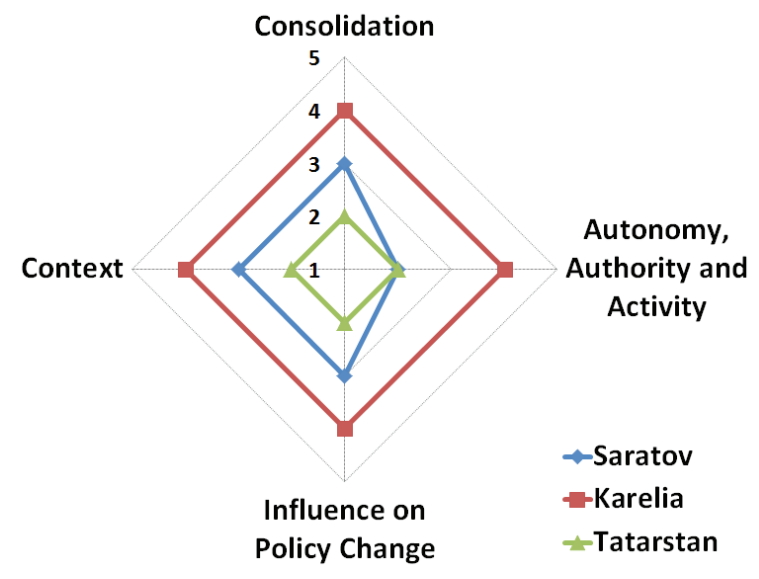

Source: the authors

The diagram clearly shows that the analytical community of Karelia has a lot of potential and actual impact on the policy process; this is due to more favourable political context, more resource capacity, and high level of community consolidation. Analytical communities of Saratov experience serious difficulties, especially related to their dependent status from the governmental actors, but still they are in more favourable context when compared with Tatarstan. In Saratov, the communities have difficulties of consolidation. Altogether, this results in limited opportunities for the community to impact on policy making.

The analytical communities of Tatarstan are in the process of formation and development. Poor political context and the dependence of all non-state actors from a single regional centre of power don't contribute to the development of analytical communities in Tatarstan. This negates the existing efforts of analysts to influence policy change. Any serious impact of analysts on policy change is possible if they are fully incorporated into power structures, but then the analysts will lose their autonomous status and become civil servants of the state, with all its consequences. 


\section{CONCLUSION}

There is a very strong association between political competition and pluralism as well as well-performed democratic institutions in the region; the level of consolidation of analytical community, its autonomous political status and authority - on the one hand, and analytical capacity to perform policy impact in policy change in the region. In Karelia, all these factors as compared with Saratov and Tatarstan are more favourable; that is why, in Karelia, relatively more consolidated analytical communities are more capable to propose alternatives to governmental policies and decisions. In Saratov, the divided analytical communities are working in the interests of their patrons. In Tatarstan, the separated analysts embedded in the vertical of power are working in their interests.

We cannot say that only analytical communities in Karelia influence policy change in the region. Each region represents a unique model of integration of analytical communities in policy making. In Karelia, the function of analytical communities is to propose alternative decisions, policies and strategies for the government. In Saratov, it is the consulting and support of the political activities of the patrons; while in Tatarstan, it is the legitimizing of the governmental political decisions and the development of governmental policy projects. But only in Karelia, the analytical communities enjoy autonomy from the government and other political actors.

As political competition and pluralism, supported by democratic institutions, and consolidated analytical community are some crucial determinants for regional analytical communities to produce independent policy advice, the study of other democratic regions of Russia can test the Karelia model. First of all, some regions of the Urals and Siberia, the absolute leaders of rankings of democracy in the Russian regions, could be added in the research design (such as Sverdlovsk Oblast, Perm, Irkutsk, Krasnoyarsk, and Novosibirsk) (Petrov \& Titkov 2013). The Saratov model can be verified by adding other Volga regions that are more democratic than Saratov, such as Samara Oblast, Yaroslavl, and Nizhniy Novgorod. Also, these regions have well-developed academic infrastructure, that is why we can assume the existence of a more consolidated analytical community there. The study of analytical communities in these regions can reveal more model roles of the analytical communities' impact on policy making.

Also, the method to evaluate policy impact of analytical communities in these three regions of Russia may be applied to nonwestern societies, because such parameters as the level of political competition and pluralism and consolidation of community are not embedded in non-western polities, but are crucial for the development of autonomy of the analytical communities. This is a key prerequisite to provide independent policy advice. Moreover, this method can be used not only for analytical but also for epistemic and other intellectual communities. It can be applied to a greater diversity of political actors and the assessment of policy impact of analytical communities in particular policy fields, such as STI policy (Zaytsev et al., 2016), education policy, or migration policy. Further research is important to test this statement.

\section{NOTE}

The study has been funded by the Russian Academic Excellence Project '5-100'.

\section{REFERENCES}

Belyaeva N. (ed.). (2013). Analytical communities in public policy: global phenomenon and Russian practices [in Russian]. Moscow, Russia: ROSSPEN.

Belyaeva, N. (2011). Analysts: 'Consultants' or 'Independent Policy Actors'. PolitickaMisao, 48(5), 125-140.

Dahl, R. (1989). Democracy and its critics. New Haven and London: Yale University Press.

Fligstein N. (1997). Fields, Power, and Social Skill: A Critical Analysis of The New Institutionalisms. Assessed 11 February 2017: http://www.irle. berkeley.edu/culture/papers/Fligstein3.pdf.
Haas, P. (1992). Epistemic Communities and International Policy Coordination. International Organization, 46(1), 1-35.

Hoppe, R. (2009). Scientific advice and public policy: expert advisers and policymakers' discourses on boundary work. Poiesis Praxis, 6, 235-263.

Howlett, M. \& Craft, J. (2013). The dual dynamics of policy advisory systems: the impact of externalization and politicization on policy advice. Policy and Society, 32, 187-197.

Kakabadze Sh. \& Zaytsev D. \& Zviagina N. \& Karastelev V. (2011). Institute of civil participation: test of actors' activity [in Russian]. Polis, 3(123), 88-108. 
Ledyaev V. (2012). Sociology of power. Theory and experience of empirical research of power in local communities [in Russian]. Moscow, Russia: Higher School of Economics.

McGann J. \& Johnson E. (2006). Comparative Think Tanks, Politics and Public Policy. Cheltenham, UK; Northampton, MA, USA: Edward Elgar Pub.

McGann J. \& Sabatini R. (2010). Global Think Tanks. Policy Networks and Governance. London, New York: Routledge, Taylor \& Francis Group.

McGann, J. (2016).2015 Global Go To Think Tank Index Report. TTCSP Global Go To Think Tank Index Reports. Paper 10. Assessed 11 February 2017: http://repository.upenn.edu/think_tanks/10.

Petrov N. \& Titkov A. (2013). Ranking of democracy in Russian regions. Moscow Carnegie Centre. Assessed 11 February 2017: http://carnegie. ru/2013/12/25/ru-pub-55853

Rich A. (2004). Think Tanks, Public Policy, and the Politics of Expertise. Cambridge, UK: Cambridge University Press.

Rich A. \& Weaver K. (1998). Advocates and Analysts: Think Tanks and the Politicization of Expertise. In A. J. Cigler \& B. A. Loomis (Eds.), Interest Group Politics. Washington D.C.: CQ Press.

Stone D. \& Denham A. (Eds.). (2004). ThinkTankTraditions: Policy Research and the Politics of Ideas. Manchester, UK: Manchester University Press.

Suhorukov A. (2011). Regional analytical communities as policy actors: criterion, stages of development, conditions (case study of Karelia) [in Russian]. Polis, 3(123), 109-114.

Titkov A. \& Tereschenko E. (2013a) Political environment in the Republic of Karelia: 'modest competition based on rules'. In Belyaeva N. (Ed.), Analytical communities in public policy: global phenomenon and Russian practices [in Russian] (pp. 196-198). Moscow, Russia: ROSSPEN.

Titkov A. \& Tereschenko E. (2013b) Political environment in the Republic of Tatarstan: 'effective East Asian capitalism'. In Belyaeva N. (Ed.), Analytical communities in public policy: global phenomenon and Russian practices [in Russian] (pp. 171-175). Moscow, Russia: ROSSPEN.

Titkov A. \& Tereschenko E. (2013C) Political environment in Saratov oblast: 'fights without rules'. In Belyaeva N. (Ed.), Analytical communities in public policy: global phenomenon and Russian practices [in Russian] (pp. 146-148). Moscow, Russia: ROSSPEN.

Zaytsev D. \& Belyaeva N. \& Ena O. \& Chulik A. (2016). Analytical communities' impact assessment of policy change [in Russian]. Public Administration Issues, 1, 103-128.

Zaytsev, D. (2010).ThinkTanks in Politics. Characteristics and Evaluation of Policy Process Impact. Saarbrucken, Germany: LAP LAMBERT Academic Publishing.
Zaytsev, D. (2012). Analytical Communities in the Local Policy Process: Creating Self-identity. International Journal of Business and Social Science, 3(5), 208-221. 